\title{
Faculty Development for Hospitalists: A Call to Arms
}

\author{
Jennifer S. Myers, MD*, S. Ryan Greysen, MD
}

Section of Hospital Medicine; Perelman School of Medicine, University of Pennsylvania, Philadelphia, Pennsylvania.

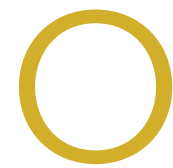

ver the past two decades, the field of hospital medicine has gone from relative obscurity to a viable career pathway for approximately 50,000 physicians in this country. ${ }^{1}$ A subset of hospitalists pursue careers in academic medicine, which is a pathway that traditionally includes education and scholarship in addition to patient care. While the academic career pathway is well paved in many clinical specialties, it is still relatively underdeveloped for academic hospitalists, and thus what defines career success for this group is even less clear.

In this issue of the Journal of Hospital Medicine, Cumbler et al. performed a qualitative analysis to explore how early career academic hospitalists self-define and perceive their career success. ${ }^{2}$ Drawing on interviews with 17 early-career hospitalists at 3 academic medical centers, the authors created a theoretical framework organized around a traditional conceptual model of career success that is divided into intrinsic and extrinsic motivating factors. They found that early-career academic hospitalists, (clinician-educators in first 2-5 years), defined their career success almost exclusively around factors intrinsic to their dayto-day job. These factors included such things as excitement about their daily work, developing proficiency in the delivery of high-quality clinical care, and passion for doing work that is meaningful to them. In addition to these immediate job satisfiers, many hospitalists emphasized long-term career success factors such as becoming an expert in a particular domain of hospital medicine and gaining respect and recognition within their local or national environment. Surprisingly, compensation and career advancement through promotion, two traditional external career success factors, were not uniformly valued.

These findings come at a critical time for our field in which early-career faculty outnumber mid- and late-career faculty by an order of magnitude. Indeed, how to develop, promote, sustain, and retain young hospitalists is a topic on the minds of most hospital medicine group directors. Putting aside the impact of hospitalist turnover on productivity, patient care outcomes, and morale within an individual hospital medicine

\footnotetext{
*Address for correspondence: Jennifer S. Myers, MD, Professor of Clinical Medicine, Section of Hospital Medicine, Division of General Internal Medicine, Perelman School of Medicine, University of Pennsylvania. 3400 Spruce Street, Maloney Building Suite 5033, Philadelphia, PA 19104; Telephone: (215)662-3797; Fax (215) 662-6250; Email: Jennifer.myers@uphs.upenn.edu
}

Additional Supporting Information may be found in the online version of this article.

Received: February 9, 2018; Accepted: February 15, 2018

@2018 Society of Hospital Medicine DOI 10.12788/jhm.2973 group, we agree with the authors that understanding and cultivating career success for academic hospitalists is imperative for the future of our field. For this reason, we launched a formal faculty development program at Penn this year, which focuses on supporting the growth of hospitalists in their first two years on faculty. The findings of this study provide interesting new perspectives and encourage us to continue our focus on early-career academic hospitalists. We laud the previous efforts in this area and hope that the paper by Cumbler et al. encourages and inspires other programs to start or accelerate their hospitalist faculty development efforts. ${ }^{3-5}$

However, some findings from this study are somewhat perplexing or even a bit discouraging for those who are invested in faculty development in academia. For example, the authors raise the possibility that there may be a disconnect in the minds of early-career hospitalists as it pertains to their thoughts on career success. On the one hand, the hospitalists interviewed in this study are happy doing their clinical work and cite this as a primary driver of their career success. On the other hand, they equate career success with things such as developing expertise within a particular domain of hospital medicine, acquiring leadership roles, collaborating academically with other specialties or professions, or developing new innovations. Presumably this is part of the reason that they selected a job in an academic setting as opposed to a community setting. However, in order to achieve these goals, one must devote time and effort to purposefully developing them. Therefore, identifying and developing mentors who can assist early-career hospitalists with identifying, articulating, and developing strategies to achieve both their short- and long-term career goals is critical. One mentor-mentee conversation may reveal that an individual hospitalist values being an excellent clinician and has little interest in developing a niche within hospital medicine; another may reveal a lack of awareness of available professional development resources; still another may uncover a lack of realism regarding the time or skills it takes to achieve a particular career goal. These realities highlight an imperative for our field to develop robust and sustainable mentorship programs for not only early-career hospitalists but also some mid-career hospitalists whose careers may not yet be fully developed. Indeed, one of the biggest challenges that have emerged in our experience with a faculty development program at Penn is creating meaningful mentorship and career development advice for mid-career hospitalists (late assistant or early associate professors who are typically 5-10 years into their careers).

We found it interesting that the hospitalists interviewed did not mention three of the four pillars of career satisfaction outlined in the white paper on Hospitalist Career Satisfaction 
from the Society for Hospital Medicine: workload schedule, autonomy control, and community/environment. ${ }^{6}$ Perhaps this is because hospitalists, like many other professionals, recognize that feeling satisfied in one's career is not the same as feeling successful. Satisfaction in one's career refers to the foundational needs that one requires in order to feel content, whereas success is more often equated with achievement, even if that achievement is simply the acquisition of one's goals for themselves. The reality is that given the constant growth and change within teaching hospitals, and therefore academic hospital medicine groups, tending to the satisfiers for hospitalists (eg, schedule and workload) often takes a front seat to assisting faculty in achieving their individual career potential. We assert that despite the inherent difficulty, academic hospital medicine group leaders need to focus their attention on both the satisfaction and career success of their early-career faculty.

Finally, this paper raises many interesting questions for researchers interested in the professional development of hospitalists. Are the career success perspectives of an early-career academic hospitalist different from those of an early-career intensivist or emergency medicine physician in an academic setting? Hospital medicine has historically been likened to both fields given the similar intensity of clinical work and the fact that all three fields were created around the need for specialists in a care setting as opposed to a disease state. It is possible that the vision of success for young academic physicians as a whole has changed with the millennial generation entering the workforce. Do early-career hospitalists look different from early-career general internists in academic settings? The latter group has more promoted faculty in their division to serve as role models and mentors and who have demonstrated more success in a variety of replicable career pathways. The fact that the definition of career success may evolve over time also emerged as a theme from this paper. Do mid-career academic hospitalists find that the excitement for daily clinical work wanes over time leaving them feeling less successful and looking for something more?

In conclusion, the findings of Cumbler et al. should promote unrest among leaders of academic hospital medicine groups and their departments of medicine. While it is inspiring to see so many early-career hospitalists focused on their daily happiness at work, we are unsure about whether they have the knowledge, tools, and guidance to achieve their self-professed academic goals, which many equate with career success. Given the continued growth of the hospital medicine workforce, we view this important new work as a national call to arms for the purposeful development of academic hospitalist faculty development programs.

Disclosures: Dr. Myers and Dr. Greysen have nothing to disclose.

\section{References}

1. Wachter RM, Goldman L. Zero to 50,000-The 20th anniversary of the hospitalist. N Engl J Med. 2016;375(11):1009-1011.

2. Cumbler $E$, Yirdaw $E$, Kneeland $P$, et al. What is career success for academic hospitalists? A qualitative analysis of early-career faculty perspectives. J Hosp Med. 2018;13(5):372-377. doi: 10.12788/jhm.2924. Published online first January 31, 2018.

3. Nagarur A, O'Neill RM, Lawton D, Greenwald JL. Supporting faculty development in hospital medicine: design and implementation of a personalized structured mentoring program. J Hosp Med. 2018;13(2):96-99.

4. Sehgal NL, Sharpe BA, Auerbach AA, Wachter RM. Investing in the future: building an academic hospitalist faculty development program. J Hosp Med. 2011;6(3):161-166

5. Howell E, Kravet S, Kisuule F, Wright SM. An innovative approach to supporting hospitalist physicians towards academic success. J Hosp Med. 2008;3(4):314-318.

6. Society of Hospital Medicine Career Satisfaction Taskforce: A Challenge for a new Specialty. A White paper on hospitalist career satisfaction. http://dev.hospitalmedicine.org/Web/Media_Center/shm_white_papers. aspx. Accessed February 9, 2018. 